The Training Courses

of Urological Laparoscopy 

Ying Hao Sun • Arthur D. Smith

Editors

\section{The Training Courses of Urological Laparoscopy}

Springer 


\section{Editors}

Ying Hao Sun, M.D.

Department of Urology

Changhai Hospital

Shanghai

China

Arthur D. Smith, M.D.

Department of Urology

Arthur Smith Institute of Urology

Long Island Jewish Medical Centre

New Hyde Park, NY, USA
Associate Editor

Bo Yang, M.D.

Department of Urology

Changhai Hospital

Shanghai

China

ISBN 978-1-4471-2722-2

ISBN 978-1-4471-2723-9 (eBook)

DOI 10.1007/978-1-4471-2723-9

Springer Dordrecht Heidelberg New York London

Library of Congress Control Number: 2012941849

(c) Springer-Verlag London 2012

This work is subject to copyright. All rights are reserved by the Publisher, whether the whole or part of the material is concerned, specifically the rights of translation, reprinting, reuse of illustrations, recitation, broadcasting, reproduction on microfilms or in any other physical way, and transmission or information storage and retrieval, electronic adaptation, computer software, or by similar or dissimilar methodology now known or hereafter developed. Exempted from this legal reservation are brief excerpts in connection with reviews or scholarly analysis or material supplied specifically for the purpose of being entered and executed on a computer system, for exclusive use by the purchaser of the work. Duplication of this publication or parts thereof is permitted only under the provisions of the Copyright Law of the Publisher's location, in its current version, and permission for use must always be obtained from Springer. Permissions for use may be obtained through RightsLink at the Copyright Clearance Center. Violations are liable to prosecution under the respective Copyright Law.

The use of general descriptive names, registered names, trademarks, service marks, etc. in this publication does not imply, even in the absence of a specific statement, that such names are exempt from the relevant protective laws and regulations and therefore free for general use.

While the advice and information in this book are believed to be true and accurate at the date of publication, neither the authors nor the editors nor the publisher can accept any legal responsibility for any errors or omissions that may be made. The publisher makes no warranty, express or implied, with respect to the material contained herein.

Printed on acid-free paper

Springer is part of Springer Science+Business Media (www.springer.com) 


\section{Preface}

Since the early 1990s, with the introduction of laparoscopic techniques, laparoscopy has been a rapidly evolving area of urology. Even for more difficult advanced procedure, such as partial nephrectomy and radical prostatectomy, laparoscopy has become an option in hands of skilled surgeons. With the popularity of this technique, residents have been required to develop more skills in less time. However, issues of patient safety, costs, time constraints, and logistics have inevitably limited training opportunities for the novices in the operating room (OR). And most surgical textbooks just provide some standard methods of performing an operation or some surgical tricks and tips. It is more critical to teach residents how to gain enough surgical skills to reduce the complication during the initial stage. And with the increasing use of the laparoendoscopic single-site surgery (LESS) and robotic surgery in the urology, appropriate training programs also need to be established for mastery of these new technologies.

In pursuit of this goal, we sought to provide a special book which is very strong on details of training and will provide a benchmark, a line in the sand. This book takes some experts in laparoscopic urology together from across the world to share their ideas and experience of training, from basic stems in the dry lab through to hints and tricks for problem solving in complex scenarios. Many training models in this book can be referred, which will make the training course easier and more efficient. There is a desire among more and more residents to realize the importance of laparoscopic training and establish the individualized program with the help of this book.

We are grateful that all the contributors completed their assignment in a timely manner to ensure that this book is truly a state-of-the-art reference. I am also grateful for the time, effort, and creativity that each of the contributors put forth on behalf of the book. It has been a pleasure to work with the entire staff of Springer Publishers. Their guidance and expertise were invaluable. I would also like to thank my dear wife for her support related to this project.

Ying Hao Sun, M.D. 



\section{Contents}

1 The Role of Laparoscopy Training in Urology .................................... 1 Zhamshid Okhunov, Zeph Okeke, and Arthur D. Smith

2 How to Improve Your Laparoscopic Skills Quickly …………………. 11 Mahesh R. Desai and Arvind Prakash Ganpule

3 The Basic Laparoscopic Skills Training Module Ying Hao Sun, Huiqing Wang, and Bo Yang

4 The Advanced Laparoscopic Skills Training Module Ying Hao Sun, Liang Xiao, and Bo Yang

5 The Laparoscopic Animal Lab Training Module Ying Hao Sun, Zhenjie Wu, and Bo Yang

6 The Laparoendoscopic Single-Site Surgery (LESS) Training Module Ying Hao Sun, Bo Yang, Huiqing Wang, Liang Xiao, and Zhenjie Wu

7 Skills and Training Course in Robotic Laparoscopic Urology Ananthakrishnan Sivaraman, Rafael F. Coelho, Sanket Chauhan, Kenneth J. Palmer, and Vipul R. Patel

8 The Skills and Training Course of NOTES in Urology Estevao A.R. Lima

9 The Tips and Tricks of the Suture in Urologic Laparoscopy Eugen Yuhui Wang

10 Dissection and Hemostasis in Urologic Laparoscopy: Tips and Tricks Jian Huang 
11 Anatomic Planes and Landmarks in Urologic Laparoscopy

Gyung Tak Sung and Tae Hyo Kim

12 Urologic Laparoscopic Surgery: Analysis of the Complications........ Xin Gao

Index

193 


\section{Contributors}

Sanket Chauhan, M.D. Department of Urology, Global Robotics Institute, Florida Hospital Celebration Health, Celebration, FL, USA

Rafael F. Coelho, M.D. Departmento do Urologia, Hospital Israelita Albert Einstein, São Paulo, Brazil

Instituto do Câncer do Estado de São Paulo, São Paulo, Brazil

Department of Urology, Global Robotics Institute, Florida Hospital Celebration Health, Celebration, FL, USA

Cardeal Arcoverde, Sao Pãulo, Brazil

Mahesh R. Desai, M.S., FRCS (Edin.), FRCS (England) Department of Urology, Muljibhai Patel Urological Hospital, Nadiad, Gujarat, India

Arvind Prakash Ganpule, M.S. (Gen. Surg.), DNB (Urology) Department of Urology, Muljibhai Patel Urological Hospital, Nadiad, Gujarat, India

Xin Gao, M.D., Ph.D. Department of Urology, The Thirds Affiliated Hospital, Sun Yat-sen University, GhuangDong, GuangZhou, China

Jian Huang, M.D., Ph.D. Department of Urology, Sun Yat-sen Memorial Hospital, Sun Yat-sen University, GuangZhou, GhuangDong, China

Tae Hyo Kim, M.D. Department of Urology, Dong-A University Hospital, Seo-Gu, Busan, Korea

Estevao A.R. Lima, M.D., FEBU, Ph.D. Department of Urology, Hospital of Braga, Life and Health Sciences Research Institute (ICVS), ICVS/3B's - PT Government Associate Laboratory, School of Health Sciences, University of Minho Braga/Guimarães, Portugal

Zeph Okeke, M.D. Department of Urology, Smith Institute for Urology, North Shore - Long Island Jewish Medical Centre, Lake Success, NY, USA 
Zhamshid Okhunov, M.D. Department of Urology, Smith Institute for Urology, North Shore - Long Island Jewish Medical Centre, Lake Success, NY, USA

Kenneth J. Palmer, M.D. Department of Urology, Global Robotics Institute, Florida Hospital Celebration Health, Celebration, FL, USA

Vipur R. Patel, M.D. Department of Urology, Global Robotics Institute, Florida Hospital Celebration Health, Celebration, FL, USA

Ananthakrishnan Sivaraman, M.S., MCh, DNB, FRCS (Urol) Department of Urology, Global Robotics Institute, Florida Hospital Celebration Health, Celebration, FL, USA

Arthur D. Smith, M.D. Department of Urology, Arthur Smith Institute of Urology, Long Island Jewish Medical Centre, New Hyde Park, NY, USA

Ying Hao Sun, M.D. Department of Urology, Changhai Hospital, Shanghai, China

Gyung Tak Sung, M.D. Department of Urology, Dong-A University Hospital, Seo-Gu, Busan, Korea

Eugen Yuhui Wang, M.D., Ph.D., FEBU Department of Urology, Clinic for Urology and Andrology, Eskilstuna/Stockholm, Sweden

Centre for Clinical Research Sörmland, Uppsala University, Sweden

Huiqing Wang, M.D. Department of Urology, Changhai Hospital, Shanghai, China

Zhenjie Wu, M.D. Department of Urology, Changhai Hospital, Shanghai, China

Liang Xiao, M.E. Department of Urology, Changhai Hospital, Shanghai, China

Bo Yang, M.D. Department of Urology, Changhai Hospital, Shanghai, China 